\title{
MALARIA IN WANOKAKA AND LOLI SUB-DISTRICTS, WEST SUMBA DISTRICT, EAST NUSA TENGGARA PROVINCE, INDONESIA
}

\author{
DIN SYAFRUDDIN,* PUJI B. S. ASIH, FARAH N. COUTRIER, LEILY TRIANTY, RINTIS NOVIYANTI, YAVETH \\ LUASE, WAJIYO SUMARTO, MARTEN CALEY, ANDRE J.A.M. VAN DER VEN, AND ROBERT W. SAUERWEIN \\ Eijkman Institute for Molecular Biology, Jakarta, Indonesia; Department of Parasitology, Faculty of Medicine, Hasanuddin \\ University, Tamalanrea, Makassar, Indonesia; West Sumba District Health Department, Waikabubak, West Sumba District, Indonesia; \\ University Medical Centre St. Radboud, Nijmegen, The Netherlands
}

\begin{abstract}
Malaria has long been known as one of the major public health problems in West Sumba District, East Nusa Tenggara Province, Indonesia. To obtain baseline data for establishment of a suitable malaria control program in the area, malariometric surveys were conducted in two sub-districts, Wanokaka and Loli, during the periods of January, May, and August 2005. The survey included three selected villages in each sub-district, and blood smear analyses of 701 , 921, and 894 randomly selected subjects in January, May, and August revealed 30.5\%, 25.3\%, and 28.2\% malaria positives, respectively, consisting mainly of Plasmodium falciparum and P. vivax, and in a few cases, $P$. malariae. Analysis of malaria prevalence at different age groups clearly reflected the common phenomenon that younger individuals are more vulnerable by infection of either $P$. falciparum or $P$. vivax. In falciparum malaria, the frequency of cases carrying gametocytes was also relatively high involving all age groups. The findings indicate that the malaria incidence and transmission in the area are relatively high and that further exploration is warranted to establish a precise malaria control program.
\end{abstract}

\section{INTRODUCTION}

Malaria represents a major health problem in the East Nusa Tenggara Province of Indonesia, where the highest malaria incidence was reported in the last few years. ${ }^{1}$ In the West Sumba District particularly, malaria was ranked first among the 10 major public health problems (West Sumba District Health Department, unpublished report, 2004) and is responsible for the majority of child mortality in the area. In 2003 , approximately 266,898 clinical malaria cases were reported, and among them, 10,151 were confirmed by microscopic examination to be positive for Plasmodium falciparum and/or $P$. vivax. Surveys performed from February to May 1998 in the Radamata Primary Health Center, Laratama sub-district, revealed the Plasmodium infection rate to be $5.1 \%$ in children 0-9 years of age. ${ }^{2}$

Despite several efforts by local and national authorities to control malaria incidence, malaria remains one of the major diseases causing death in the area. Several factors may contribute to this situation, such as uncontrolled use of antimalarial drugs, anti-malarial drug resistance, and inadequate vector control measures. With the current national policy to transfer most of the authority to the local district government, several problems are coming to surface, most notably the preparedness of local facilities to manage the health problems.

In an attempt to establish a sustainable, evidence-based malaria control program in the area, we initiated a survey to obtain baseline data regarding malaria incidence, mosquito vector, host genetic, and socio-cultural factors that may contribute to malaria morbidity. We report the results of our preliminary survey in the Loli and Wanokaka sub-districts.

\section{MATERIALS AND METHODS}

Study sites. West Sumba District is one of the malaria endemic areas in the East Nusa Tenggara Province of Indonesia.

* Address correspondence to Din Syafruddin, Eijkman Institute for Molecular Biology, Jalan Diponegoro 69, Jakarta, Indonesia. E-mail: din@eijkman.go.id
The district is located in the western half of Sumba Island, and its capital is Waikabubak. Geographically, it is located at $9^{\circ} 18^{\prime}$ south latitude in the north and $10^{\circ} 20^{\prime}$ south latitude in the south and $108^{\circ} 55^{\prime}$ east longitude in the west and $120^{\circ} 23^{\prime}$ east longitude in the east. It occupies an area of $4,051 \mathrm{~km}^{2}$ and was inhabited by a total population of 385,006 in 2003 (Figure 1 ). The majority of the residents are farmers. The climate is pleasantly cool during the rainy season, namely from December to April. The temperature centers around $18-20^{\circ} \mathrm{C}$ during the cold months and around $25-33^{\circ} \mathrm{C}$ during the dry season. The average yearly rainfall in West Sumba ranges from 1,2002,450 mm. West Sumba boasts plains, mountains, hills, and valleys.

Administratively, the West Sumba district is divided into 15 kecamatans (sub-districts), and there are 16 primary health centers and 4 hospitals that provide medical and health services to the people. The main childhood diseases are malaria, respiratory illnesses, dysentery, tuberculosis, measles, and malnutrition. Two sub-districts, each represented by three villages, were selected in this study based on the reported high malaria endemicity, environmental condition, and accessibility to medical services. The villages are located either inland or along the southern coastal area of Sumba Island. The average population of each village is 1,500 people.

Malariometric surveys. Malariometric surveys were conducted during January 4-12, May 4-12, and August 3-12, 2005, and a total of 701, 921, and 894 subjects, respectively, with ages ranging from 1 month to 89 years were randomly selected from six villages in two sub-districts, Wanokaka and Loli. Thick and thin blood smears and blood blots on filter paper (3MM; Whatman, Hillsboro, OR) were obtained from each subject by finger prick. This study was carried out with the approval from the Eijkman Institute for Molecular Biology Research Ethics Committees (Jakarta, Indonesia).

Parasite detection. Thick and thin blood smears taken during the malariometric survey were stained with Giemsa and subsequently examined by light microscopy. Parasite density was determined by counting the number of parasites per leukocytes in 100 high-power microscopic fields in a Giemsastained thick film, assuming an average of 20 leukocytes per 


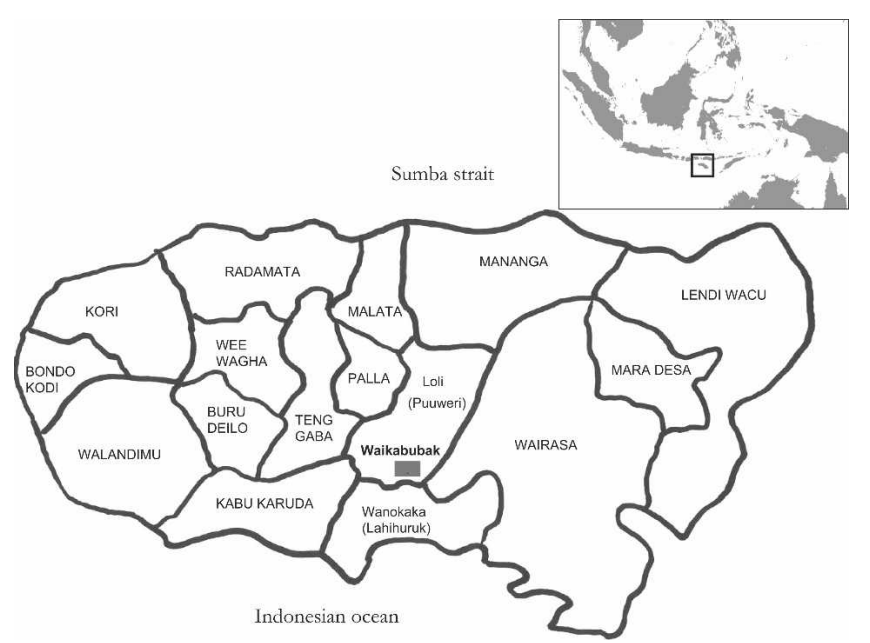

Figure 1. A sketch map of the West Sumba District and its geographic location within the Indonesia archipelago (inset). The map shows the administrative division of the district into sub-districts, whereby in each sub-district, a public health center provide medical and health service for the public. Loli sub-district (Puuweri) is located entirely inland, whereas Wanokaka (Lahihuruk) has several villages along the southern coast of the Sumba island.

microscopic field and 8,000 leukocytes/ $\mu \mathrm{L}$ of blood. Slides were declared negative if parasites could not be detected in 100 microscopic fields. The parasite count was classified as follows: +, 1-10 parasites were found per 100 thick film fields; ,$++ 11-100$ parasite were found per 100 microscopic thick film fields; +++, 1-10 parasite were found per 1 thick film fields; ++++ , more than 10 parasites were found per 1 thick film fields. ${ }^{3}$

\section{RESULTS}

A total of 701, 921, and 894 blood smears from six villages of the Wanokaka and Loli sub-districts were examined in January, May, and August, 2005, respectively, for the presence of malaria parasites by light microscopy. Our results revealed a slide positivity rate in the first survey of $30.5 \%$, consisting of $138(19.7 \%)$ cases of $P$. falciparum, $68(9.7 \%)$ cases of $P$. vivax, $1(0.1 \%)$ case of $P$. malariae, and $7(0.99 \%)$ cases of $P$. falciparum and $P$. vivax mixed infection, with the highest prevalence of $35 \%$ found in Waihura village (Table 1) and the lowest prevalence found in Baliledo. In the second survey in May 2005, the slide positivity rate was $25.3 \%$, consisting of 157 (17\%) cases of P. falciparum, 52 (5.6\%) cases of $P$. vivax, and $24(2.6 \%)$ cases of $P$. falciparum and $P$. vivax mixed infection. In the August survey, the slide positivity rate was $28.2 \%$, consisting of $149(16.7 \%)$ cases of $P$. falciparum, $84(9.4)$ cases of $P$. vivax, $5(0.5 \%)$ cases of $P$. malariae, 12 $(1.3 \%)$ cases of $P$. falciparum and $P$. vivax mixed infection, 1 case of $P$. falciparum and $P$. malariae mixed infection, and 1 case of $P$. vivax and $P$ malariae mixed infection. The malaria prevalence in different age groups is shown in Table 2. In all three surveys, more than one half of the positive samples were from the age group of less than 10 years old.

Falciparum malaria. Infection with $P$. falciparum was found in 138, 157, and 149 subjects during the first, second, and third surveys, respectively, and was the predominant species in all villages examined except in the Tanarara and Ubupede vil- lages in the third surveys. Based on age group, almost $58 \%$ of the cases occurred in children less than 10 years old (Table 2). Cases with heavier infection or parasitemia at least +++ were found in $8.6 \%$ of the subjects and almost exclusively associated with younger age groups. During the entire survey, we detected 32 cases of $P$. falciparum where blood smears indicated ovalocytic red blood cells. Among these, five cases indicated the presence of the schizont stage. The proportion of infected cases that harbored gametocytes was also relatively high $(35.5 \%)$, and more than one half of the gametocyte carriers involved younger age groups (Figure 2).

Vivax malaria. Infection with $P$. vivax was found in $9.7 \%$, $5.6 \%$, and $9.4 \%$ of the subjects, respectively, during the first, second, and third survey (Table 1), and among these, few cases harboured gametocytes. The highest $P$. vivax infection was found in Ubupede village in the third survey, whereby the infection constituted approximately $59.3 \%$ of the total malaria cases. In each village, the majority of the malaria cases were mainly confined to the age group of less than 10 years.

Mixed infection. Concomitant infection of $P$. falciparum with either $P$. vivax or $P$. malariae was found in 7 (1\%), 24 $(2.6 \%)$, and $14(1.5 \%)$ of the subjects during the first, second, and third surveys, respectively, from all villages. Most of the cases occurred in children less than 5 years of age.

Malariae malaria. Infection with $P$. malarie was found in only one $(0.1 \%)$ and seven $(0.78 \%)$ cases in the first and third surveys, respectively. The cases were found both in the Loli and Wanokaka sub-districts. In most cases, all blood stages of the parasites were found.

\section{DISCUSSION}

Malaria is widely known as a major disease causing death among children in the island of Sumba, Indonesia, but very few if any documented studies on this subject have been available to date. In an attempt to establish a sustainable malaria control program in the area, we have initiated preliminary surveys to obtain baseline data associated with the malaria endemicity in two sub-districts of West Sumba district during three different times in January, May, and August 2005, by performing mass blood survey on voluntarily joined inhabitants of six selected villages. In each survey, we shared high (25.3-30.5\%) slide positivity rates among the subjects examined. The rate was similar in each village examined but was much higher than the $7 \%$ in Loli and $9.5 \%$ in Wanokaka sub-districts of laboratory-confirmed malaria cases reported during 2004 (West Sumba Health Department Report, unpublished report, 2004). A previous study in the Radamata sub-district also reported a significantly lower endemicity. ${ }^{2}$ There are several explanations for this relatively high prevalence: first, the previous survey might have been conducted during the dry season when malaria incidence in the area was at its lowest. However, our findings are similar to the reports of clinical malaria cases from the public health centers that indicate a relatively constant of high incidence all year long. Second, the malaria cases may have been under-reported because of the difficult access to health facilities, inadequate facility for microscopic diagnosis, and the lack of properly trained microscopists. The fact that, among the 7,810 clinical cases in the Loli sub-district in 2004 , only $21.5 \%$ were confirmed by microscopy, clearly indicates the need for the de- 
TABLE 1

Malaria prevalence in Wanokaka and Loli sub-districts, West Sumba district, East Nusa Tenggara Province, Indonesia

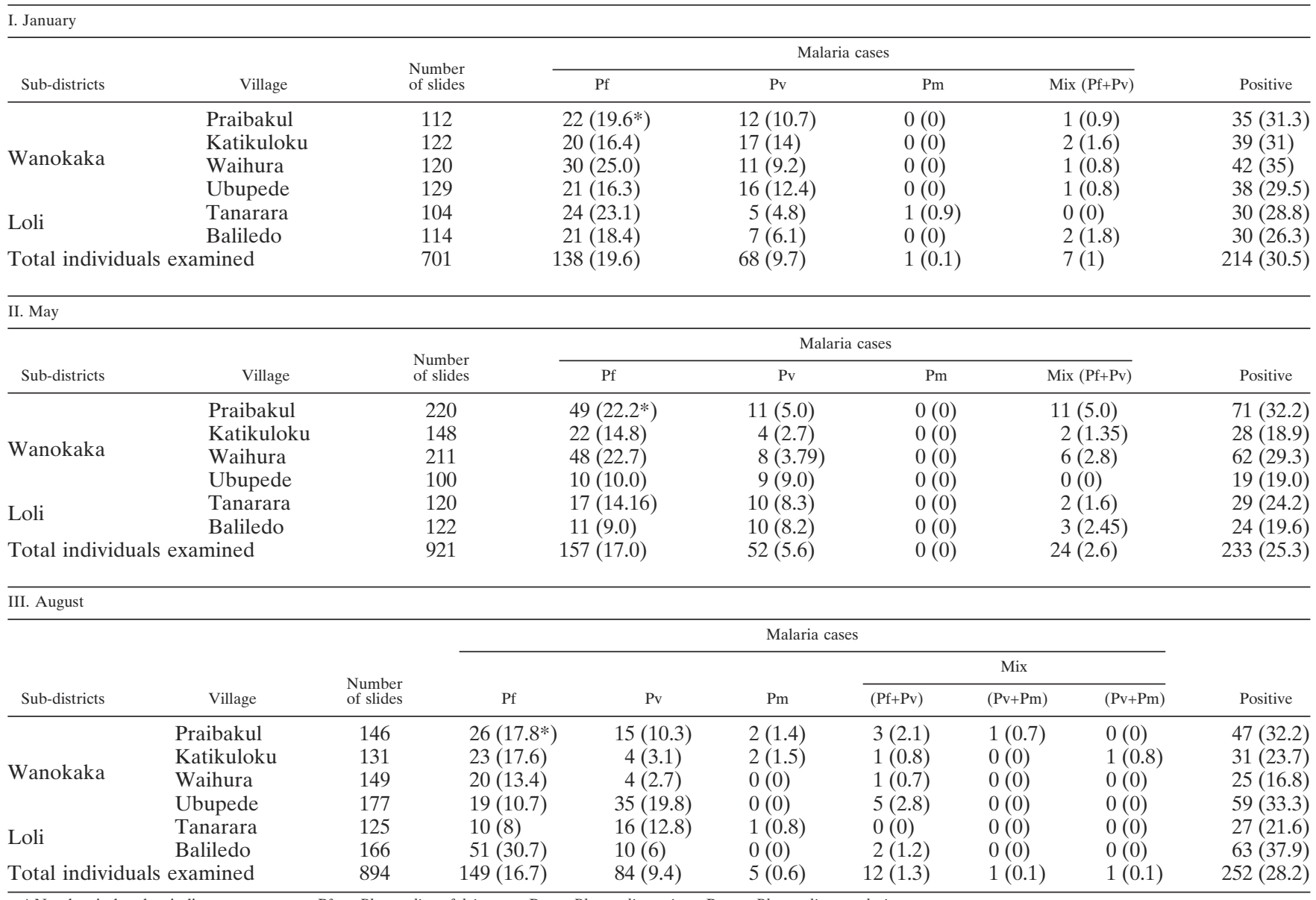

$*$ Number in bracket indicates percentage, $\mathrm{Pf}=$ Plasmodium falciparum $; \mathrm{Pv}=$ Plasmodium vivax $; \mathrm{Pm}=$ Plasmodium malariae.

velopment of quality assurance program for microscopic diagnosis to ensure the proper antimalarial deployment and monitoring in this area. During the implementation of this study, we conducted several training sessions for malaria microscopic diagnosis to improve the proficiency of the local health officials.

As in many other areas in Indonesia, malaria treatment in West Sumba follows the Indonesia Ministry of Health guidelines. ${ }^{4}$ The first line therapy is currently still chloroquine, sulfadoxine-pyrimethamine, and primaquine. Although there have been attempts to implement the artemisinin-based com- bination therapy as the first line anti-malarial drug in this area, several problems such as accessibility for microscopic diagnosis, proper monitoring, and the compliance of the patients still hinder its implementation. Malaria treatment in this area is usually given without monitoring and, in many cases, without prior laboratory or microscopic confirmation. Resistance or treatment failures to chloroquine and sulfadoxine-pyrimethamine drugs have also been reported in this area; however, there have been limited studies associated with this important issue. ${ }^{1,2,5} \mathrm{We}$ addressed this issue by conducting in vitro and in vivo drug sensitivity tests for the parasite samples

TABLE 2

Percentage of the total malaria infection by age group and Plasmodium species

\begin{tabular}{|c|c|c|c|c|c|c|c|c|c|c|c|c|c|c|c|c|c|c|}
\hline \multirow{2}{*}{$\begin{array}{l}\text { Age group } \\
\text { (from } \geq \text { to }<\text { ) }\end{array}$} & \multicolumn{3}{|c|}{ P. falciparum (\%) } & \multicolumn{3}{|c|}{ P. vivax $(\%)$} & \multicolumn{3}{|c|}{ P. malariae (\%) } & \multicolumn{3}{|c|}{ Mix PF+Pv (\%) } & \multicolumn{3}{|c|}{ Mix Pf+Pm (\%) } & \multicolumn{3}{|c|}{ Mix Pv+Pm (\%) } \\
\hline & $I^{*}$ & II & III & I & II & III & I & II & III & I & II & III & I & II & III & I & II & III \\
\hline $0-10$ & $80(58)$ & $83(53)$ & $81(54)$ & $48(70.6)$ & $36(73.5)$ & $57(68.7)$ & 0 & 0 & $2(1.4)$ & $7(100)$ & $18(78.3)$ & $6(46)$ & 0 & 0 & $1(0.7)$ & 0 & 0 & $1(0.8)$ \\
\hline $10-20$ & $18(13)$ & $44(28)$ & $36(24)$ & $5(7.3)$ & $7(14.3)$ & $18(21.7)$ & 0 & 0 & $1(0.7)$ & 0 & $4(17.3)$ & $6(46)$ & 0 & 0 & 0 & 0 & 0 & 0 \\
\hline $20-30$ & $21(15)$ & $11(7)$ & $18(12)$ & $4(5.9)$ & $3(6.1)$ & $3(3.7)$ & 0 & 0 & $1(0.7)$ & 0 & $1(4.3)$ & 0 & 0 & 0 & 0 & 0 & 0 & 0 \\
\hline $30-40$ & $9(6.5)$ & $5(3)$ & $10(6.7)$ & $2(2.9)$ & $2(4.1)$ & $3(3.7)$ & $1(0.9)$ & 0 & 0 & 0 & 0 & 0 & 0 & 0 & 0 & 0 & 0 & 0 \\
\hline $40-50$ & $1(0.7)$ & $8(5)$ & $4(2.7)$ & $3(4.4)$ & $1(2)$ & $2(2.4)$ & 0 & 0 & 0 & 0 & 0 & $1(7.7)$ & 0 & 0 & 0 & 0 & 0 & 0 \\
\hline $50-60$ & $2(1.4)$ & $3(2)$ & $1(0.7)$ & $2(2.9)$ & 0 & 0 & 0 & 0 & 0 & 0 & 0 & 0 & 0 & 0 & 0 & 0 & 0 & 0 \\
\hline$>60$ & $7(5.1)$ & $3(1.9)$ & 0 & $4(5.9)$ & 0 & 0 & 0 & 0 & 0 & 0 & 0 & 0 & 0 & 0 & 0 & 0 & 0 & 0 \\
\hline
\end{tabular}

* Number indicates time of visit: I, II, and III, for January, May, and August 2005, respectively. 

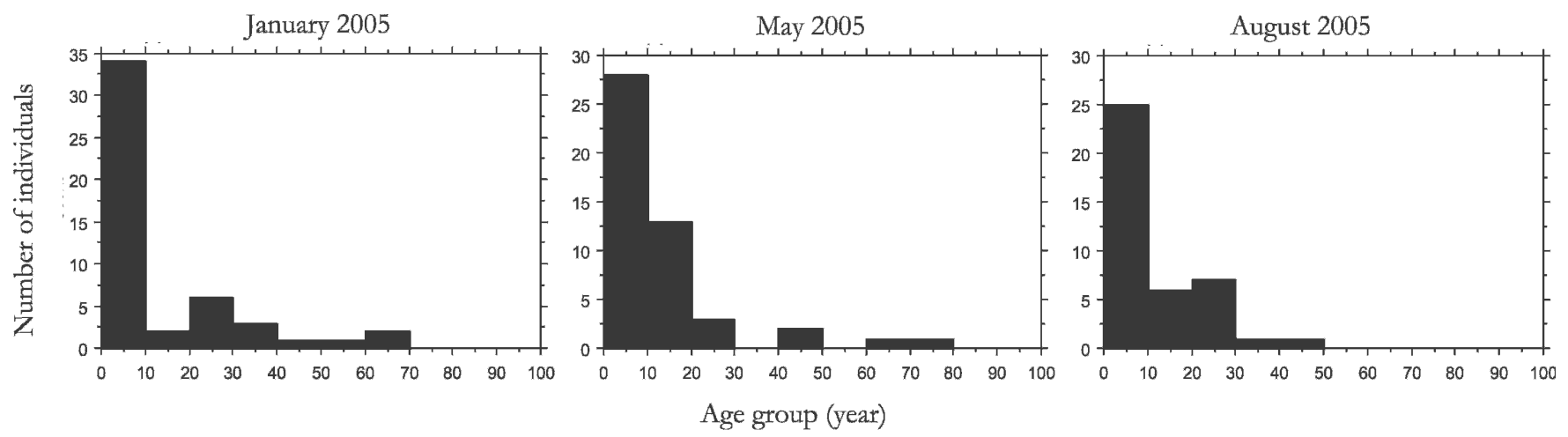

FIGURE 2. Prevalence of $P$. falciparum gametocyte carrier in different age groups at each survey. The highest prevalence was found in the 1 month to 10 years age group.

isolated from the malaria-infected individuals in the surveyed area.

The high proportion of subjects carrying $P$. falciparum gametocytes throughout the survey indicates the high potential transmission in the area. This fact is also supported by the findings that more than one half of the gametocytes carriers are in the younger age group and the living conditions in each village examined are favorable for malaria transmission, because no effective measure is being used to prevent mosquito bites. Since May 2005, the government has been distributing insecticide-treated mosquito nets (ITNs), but coverage seems far behind the need. It is also important to note that, although several species of anopheline mosquitoes have been found in this area, ${ }^{6-8}$ no systematic study on vector malaria bionomics has thus far been reported.

Studies associated with host factors that may contribute to malaria morbidity and mortality have attracted much attention. ${ }^{9}$ In Sumba, the prevalence of Southeast Asian ovalocytosis (SAO), a human genetic disorder that has been associated with malaria morbidity, was found at a frequency of $12.6 \%$ among healthy individuals. ${ }^{10}$ It was reported that the prevalence of malaria in patients with and without SAO did not differ significantly and that SAO may not interfere with the malaria susceptibility. In our study, we also found several SAO cases that were infected with malaria (data not shown), but it is important to notice the presence of schizont in some patients with SAO, a phenomenon that is rarely seen in nonSAO patients except for high parasitemia. The absence of trophozoites and schizont in the peripheral blood of falciparum malaria cases is generally associated with cytoadherence. ${ }^{11}$ It therefore may be suggested that SAO interferes with the cytoadherence of the parasite, which underlies the relative resistance of patients with SAO to cerebral complication of malaria as was shown in Papua New Guinea. ${ }^{12}$

In this study, it is also of importance to notice the eagerness of local inhabitants to participate in the survey. This aspect is somewhat different in certain areas of Indonesia where they are reluctant to participate in a survey particularly those involving blood-letting. This active participation of the local inhabitant is indeed supportive for the development of any malaria control strategy.

In conclusion, the prevalence of malaria in West Sumba is very high and urgently requires an appropriate and sustainable means of control. Several important contributing factors such as antimalarial drug policy, prevention of transmission by mosquitoes, participation of the local people, and the preparedness of the local health staff clearly represents the current malaria problem in many of malaria endemic areas in Indonesia and should be analyzed further. To circumvent the situation, a new approach in malaria control that is based on the careful assessment of the contributing factors such as the malaria parasite, the human host, the mosquito vector, and environment should be established by empowerment of the local health staff.

Received June 8, 2005. Accepted for publication January 6, 2006.

Acknowledgments: The authors thank Prof. Sangkot Marzuki of the Eijkman Institute for encouragement and support, the officials of the West Sumba District Health offices for technical support of the study; and professional health officers at the Wanokaka and Loli Public Health Center for generous assistance.

Financial support: This study is part of the PRIOR program for malaria in Indonesia and funded in-part through a grant-in-aid from the Netherlands Foundation for the Advancement of Tropical Research (NWO-WOTRO), the Netherlands Foundation for Health Research and Development (ZONMW), and the Government of Indonesia through the Ministry of Research and Technology.

Authors' addresses: D. Syafruddin, Puji B. S. Asih, Farah N. Coutrier, Leily Trianty, and Rintis Noviyanti, Eijkman Institute for Molecular Biology, Jl. Diponegoro 69, Jakarta 10430, Indonesia, E-mails: din@eijkman.go.id, puji@eijkman.go.id, farah@eijkman.go.id, leily@ eijkman, and rintis@eijkman.go.id. D. Syafruddin, Department of Parasitology, Faculty of Medicine, Hasanuddin University, Jl. Perintis Kemerdekaan Km 10, Makassar 90245, Indonesia. Yaveth Luase, Wajiyo Sumarto, and Marten Caley, West Sumba District Health Department, Waikabubak, West Sumba District, East Nusa Tenggara Province, Indonesia, E-mails: yavethl@yahoo.com, wajios@yahoo .com, and mcaley01@yahoo.com. Andre J.A.M. van der Ven and R. W. Sauerwein are at University Medical Centre, St Radboud 6500 HB, Nijmegen, The Netherlands, E-mails: A.vanderVen@AIG.umcn .nl and R.Sauerwein@mmb.umcn.nl.

Reprint requests: D. Syafruddin, Eijkman Institute for Molecular Biology, Jalan Diponegoro 69, Jakarta 10430, Indonesia. E-mail: din@eijkman.go.id.

\section{REFERENCES}

1. Syafruddin D, Asih PBS, Siregar JE, Tjitra E, 2003. Molecular basis of antimalarial drug resistance in Indonesia. Adv Exp Med Biol 531: 103-115.

2. Tjitra E, Suprianto S, Dyer M, Currie BJ, Anstey NM, 1999. Field evaluation of the ICT malaria P.f/P.v immunochromatographic test for detection of Plasmodium falciparum and Plasmodium vivax in patients with a presumptive clinical diagnosis of malaria in eastern Indonesia. J Clin Microbiol 37: 2412-2417. 
3. Gilles HM, 1993. Diagnostic method in malaria. In: Golles HM, Warrel DA, eds. Bruce-Chwatt's Essential Malariology. New York, NY: Oxford University Press; 79-95.

4. Ministry of Health, Directorate General of Communicable Disease Control and Environmental Health, Subdirectorate Malaria, 1998. Current Malaria Situation in Indonesia. Tech. Rep.

5. Tjitra E, Gunawan S, Laihad F, Marwoto H, Sulaksono S, Arjoso S, Richie TL, Manurung N, 1997. Evaluation of antimalarial drugs in Indonesia 1981-1995. Bull Penelitian Kesehatan (Indonesian) 25: 27-58

6. Atmosoedjono S, Partono F, Dennis DT, Purnomo 1977. Anopheles barbirostris as a vector of the Timor filaria on Flores Island: preliminary observations. J Med Entomol 13: 611-613.

7. Reid JA, Harrison BA, Atmosoejono S, 1979. Variation and Vector Status in Anopheles barbirostris. Mosquito Syst 11: 235-251.

8. Kirnowardoyo S, 1985. Status of Anopheles vector in Indonesia. Southeast Asian J Trop Med Hyg 16: 129-132.
9. Hill AVS, Weatherall DJ, 1998. Host genetic factors in resistance to malaria. In: Sherman IW, ed. Malaria Parasite Biology, Pathogenesis and Protection. Washington, DC: ASM Press; 445-455.

10. Kimura M, Soemantri A, Ishida T, 2002. Malaria species and Southeast Asian ovalocytosis defined by a 27-bp deletion in the erythrocyte band 3 gene. Southeast Asian J Trop Med Public Health 33: 4-6.

11. MacPherson GG, Warrel MJ, White NJ, Looareesuwan S, Warrel DA, 1985. Human cerebral malaria: aquantitative ultrastructural analysis of parasitised erythrocyte sequestration. Am J Pathol 119: 385-401.

12. Allen SJ, O'Donnell A, Alexander ND, Mgone CS, Peto TE, Clegg JB, Alpers MP, Weatherall DJ, 1999. Prevention of cerebral malaria in children in Papua New Guinea by Southeast Asian Ovalocytosis band 3. Am J Trop Med Hyg 60: 10561060. 